\title{
ESTIMATION OF STATURE FROM UPPER LIMB ANTHROPOMETRY IN MAHARASHTRIANS POPULATION: A CADAVERIC STUDY
}

\section{Sachin Tote ${ }^{1}$, Sanjay Wanjari ${ }^{* 2}$, Darshana Tote ${ }^{3}$.}

${ }^{1}$ Assistant Professor, Department of Anatomy, Jawaharlal Nehru Medical Collage, Sawangi, Wardha, Maharastra, India.

*2 Professor, Department of Anatomy, Jawaharlal Nehru Medical Collage, Sawangi, Wardha, Maharastra, India.

${ }^{3}$ Associate Professor, Department of Anatomy, Jawaharlal Nehru Medical Collage, Sawangi, Wardha, Maharastra, India.

\section{ABSTRACT}

Background: Personal identification is an essential issue when mutilated and amputated limbs or parts of the body are found in mass disasters. Estimation of the stature from the size of different parts of the body is one of the most important items in personal identification. An indirect estimation can be achieved by correlating the height with other skeletal parameters. The Humerus has easily identifiable surface landmarks which make the measurements possible in compromised postures, than in any other bones.

Materials and Methods: This study was conducted in Department of Anatomy in Jawaharlal Nehru Medical College, Maharashtra, India, over a period of 2 years. Height is measured from vertex to heal by placing two logs at the respective ends before the process of embalming. A medium size Vernier caliper is used for length estimation of humerus from heights point on head to the capitulum. Results: positive correlation was found between height and Humerus length on left and right side with some variation.

Conclusion: The study indicates that stature can be predicted accurately by linear/curvilinear and multiple regression analysis even when identity is unknown from RULL-a problem frequently encountered in medico legal investigations. Establishing identity of an individual when only some remains of the body arefound as in mass disaster, terror events, bomb explosions, accidents, wars etc. If either of the measurement is known the other can be calculated and this would be useful for forensic medicine experts and anthropologists.

KEY WORDS: Stature, Height, Upper Limb Anthropometry, Humerus Length, Cadaver.

Address for Correspondence: Dr Sanjay Wanjari, Professor, Department of Anatomy, Jawaharlal Nehru Medical Collage, Sawangi, Wardha, Maharastra, India. E-Mail: swanjari14@gmail.com

\section{Access this Article online}

\section{Quick Response code}

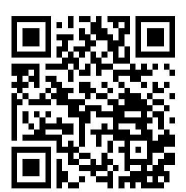

DOI: $10.16965 /$ ijar.2017.358
Web site: International Journal of Anatomy and Research ISSN 2321-4287

www.ijmhr.org/ijar.htm
Received: 18 Jul 2017

Peer Review: 19 Jul 2017

Revised: None
Accepted: 05 Sep 2017

Published (O): 01 Dec 2017

Published (P): 01 Dec 2017

\section{INTRODUCTION}

Personal identification is an essential issue when mutilated and amputated limbs or parts of the body are found in mass disasters. Estimation of the stature from the size of different parts of the body is one of the most important items in personal identification [1].
This becomes essential for archaeologists, anthropologists and forensic investigators, even when a fragment of bone is available. An indirect estimation can be achieved by correlating the height with other skeletal parameters. The Humerus has easily identifiable surface landmarks which make the measurements 
possible in compromised postures, than in any other bones. Therefore, it can be utilized to formulate the height indirectly. From many decades the estimation of person height has been linearly correlated with the length of the different long bones, especially like the ulna, the tibia, etc.[2] The linear regression equation of the height on the Humerus length has a definitive advantage over that of the tibial length, as it can be useful in the cases where the lower extremities are deformed, along with the deformities of the trunk. The current study was therefore focused on the length of the Humerus and its correlation with person stature

\section{MATERIALS AND METHODS}

This study was conducted in Department of Anatomy in Jawaharlal Nehru Medical College, Maharashtra, India, over a period of 2 years. This was a cadaver based study. The College ethical committee permission is taken prior to study. For this study all the male cadavers were selected. The selected cadavers were screened for any deformity, mutilation or disfigurement. The entire selected cadavers were acquired by the process of body donation program run by the Department of Anatomy.

As soon as the body is received by the department, body identification number is given to cadaver. Height is measured from vertex to heal by placing two logs at the respective ends before the process of embalming. Stature is measured in Centimeters and recorded. After the completion of dissection of superior extremities from both side, humerus are disarticulated, cleaned and there measurements are taken.

The obtained values were used for the statistical analysis which was done by using the one way ANOVA software. The regression equation is derived for both side humerus. A separate coefficients is calculated to estimate the person stature from length of humerus. A graph is plotted by $X$ and $Y$ axis with length of humerus and cadaver stature respectively.

\section{RESULTS AND DISCUSSION}

Positive correlation was found between height and humerus length for right side. By using one way ANOVA for regression analysis regression is found to be significant ( $F=11.40, p=0.005)$.
Height can be predicted from the equation:

Height $=50.60+3.70 *$ Humerus Length .

Positive correlation was found between height and humerus length for left side. By using one way ANOVA for regression analysis regression is found to be significant $(F=11.76, p=0.005)$. Height can be predicted from the equation:

Height $=48.11+3.75 *$ Humerus Length

\begin{tabular}{|c|c|c|c|}
\cline { 2 - 4 } & $\begin{array}{c}\text { Actual height } \\
\text { of cadaver }\end{array}$ & $\begin{array}{c}\text { Right } \\
\text { Humerus }\end{array}$ & $\begin{array}{c}\text { Left } \\
\text { Humerus }\end{array}$ \\
\cline { 2 - 4 } & 169 & 30 & 30 \\
\cline { 2 - 4 } & 152 & 29.2 & 29 \\
\cline { 2 - 4 } & 161 & 29.8 & 29.9 \\
\cline { 2 - 4 } \begin{tabular}{c} 
Table 1: \\
Showing length \\
of cadaver and \\
right \& left \\
\cline { 2 - 4 } Humerus.
\end{tabular} & 163 & 29.6 & 29.8 \\
\cline { 2 - 4 } & 164 & 29.6 & 29.7 \\
\cline { 2 - 4 } & 140 & 29.3 & 29.5 \\
\cline { 2 - 4 } & 160 & 28.8 & 26.5 \\
\cline { 2 - 4 } & 159 & 30.5 & 27.9 \\
\cline { 2 - 4 } & 160 & 29.2 & 29.2 \\
\hline & 172 & 32.8 & 32.7 \\
\hline & 158 & 30 & 30 \\
\hline & 161 & 27.8 & 27.8 \\
\hline
\end{tabular}

Table 2: Estimation of height from humerus length right side Regression Equation.

\begin{tabular}{|c|c|c|c|}
\hline $\mathbf{R}$ & R Square & $\begin{array}{c}\text { Adjusted } \\
\text { R Square }\end{array}$ & $\begin{array}{c}\text { Std. Error of } \\
\text { the Estimate }\end{array}$ \\
\hline $0.698^{\mathrm{a}}$ & 0.487 & 0.445 & 5.76 \\
\hline
\end{tabular}

Table 3: One way ANOVA.

\begin{tabular}{|c|c|c|c|c|c|}
\hline & $\begin{array}{c}\text { Sum of } \\
\text { Squares }\end{array}$ & df & $\begin{array}{c}\text { Mean } \\
\text { Square }\end{array}$ & F & p-value \\
\hline Regression & 379.745 & 1 & 379.745 & & \\
\cline { 1 - 4 } Residual & 399.469 & 12 & 33.289 & & \\
\cline { 1 - 4 } Total & 779.214 & 13 & & 11.408 & $0.005, \mathrm{~S}$ \\
\hline
\end{tabular}

Table 4: Regression Coefficient.

\begin{tabular}{|c|c|c|c|c|c|}
\hline & \multicolumn{2}{|c|}{$\begin{array}{c}\text { Unstandardized } \\
\text { Coefficients }\end{array}$} & $\begin{array}{c}\text { Standardized } \\
\text { Coefficients }\end{array}$ & \multirow{2}{*}{$\mathrm{t}$} & $\mathrm{p}$-value \\
\cline { 2 - 4 } & $\mathrm{B}$ & Std. Error & Beta & & \\
\hline Height & 50.6 & 32.23 & - & - & - \\
\hline $\begin{array}{c}\text { Humerus } \\
\text { Length }\end{array}$ & 3.7 & 1.09 & 0.698 & 3.377 & $0.005, \mathrm{~S}$ \\
\hline
\end{tabular}

Regression Equation: Height $=50.60+3.70 *$ Humerus Length (Right Side)

Table 5: Estimation of height from humerus length left side Regression Equation.

\begin{tabular}{|c|c|c|c|}
\hline $\mathbf{R}$ & $\mathbf{R}$ Square & $\begin{array}{c}\text { Adjusted } \\
\mathbf{R} \text { Square }\end{array}$ & $\begin{array}{c}\text { Std. Error of the } \\
\text { Estimate }\end{array}$ \\
\hline 0.704 & 0.495 & 0.453 & 5.72 \\
\hline
\end{tabular}


Table 6: One way ANOVA.

\begin{tabular}{|c|c|c|c|c|c|}
\hline & $\begin{array}{c}\text { Sum of } \\
\text { Squares }\end{array}$ & df & $\begin{array}{c}\text { Mean } \\
\text { Square }\end{array}$ & F & p-value \\
\hline Regression & 385.73 & 1 & 385.73 & & \\
\cline { 1 - 4 } Residual & 393.47 & 12 & 32.79 & \multirow{2}{*}{11.76} & \multirow{2}{*}{$0.005, \mathrm{~S}$} \\
\cline { 1 - 4 } Total & 779.21 & 13 & & & \\
\hline
\end{tabular}

Table 7: Regression Coefficient.

\begin{tabular}{|c|c|c|c|c|c|}
\hline & \multicolumn{2}{|c|}{$\begin{array}{c}\text { Unstandardized } \\
\text { Coefficients }\end{array}$} & $\begin{array}{c}\text { Standardized } \\
\text { Coefficients }\end{array}$ & \multirow{2}{*}{$\mathrm{t}$} & \multirow{2}{*}{ p-value } \\
\cline { 2 - 4 } & $\mathrm{B}$ & Std. Error & Beta & & \\
\hline Height & 48.11 & 32.47 & - & - & - \\
\hline $\begin{array}{c}\text { Humerus } \\
\text { Length }\end{array}$ & 3.75 & 1.1 & 0.7 & 3.42 & $0.005, \mathrm{~S}$ \\
\hline
\end{tabular}

Regression Equation: Height $=48.11+3.75 *$ Humerus Length (Left Side)

Graph 1: Correlation between height and humerus length right side Right Humerus.

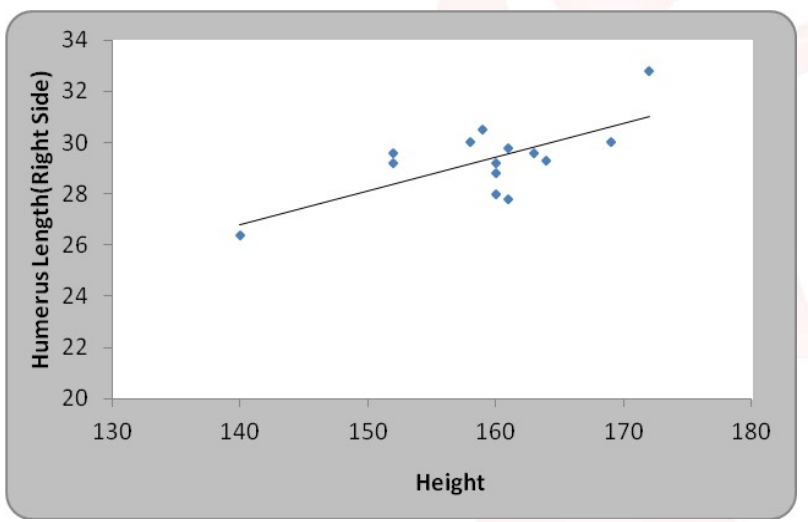

Graph 2: Correlation between heightand humerus length left side Left Humerus.

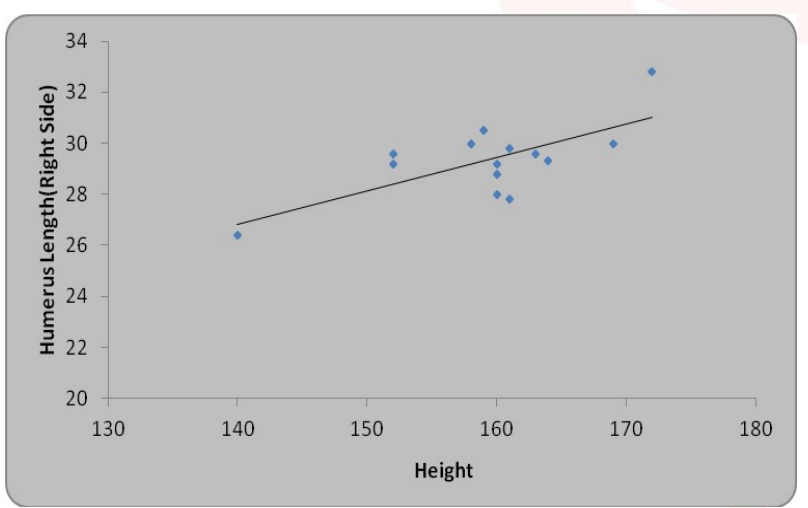

Many Studies have been conducted on the estimation of stature from the human skeleton/ percutaneous measurements. There are various methods to estimate stature but the easiest and reliable method is by regression analysis. It is clear that if either of the measurements (RULL or total height) is known, the other can be calculated and this fact may be of practical use in medico-legal investigations and in anthropometry. Multiple regression equations resulted in a better estimation of the body parts when compared with simple regression equations; thus, it is better to use multiple regression equations when possible. The stepwise analysis demonstrated an accuracy rate close to the direct approach. Upper Extremity Segments Dimensions In cases where the human remains of upper extremity are available, the estimation of a living height could be made possible by using various dimensions of the upper extremity.

Jibonkumar and Lilinchandra [3] have studied the co-relation between stature and different facial measurements among the Indian population by using regression equation and multiplication factor.

Recently, Pelin et al [4] have studied the relation between the body height and the head and face dimensions in Turkish population and found that the estimation of body height is not reliable with the help of head and face dimensions.

Agnihotri et al[5] performed the study in an IndoMauritian population to estimate the stature from the forearm length (percutaneous ulna length). llayperuma et al [6] showed the prediction of stature from incomplete and decomposing skeletal remain and found Correlation coefficient between total height and ulna length was statistically significant and positive in both males and females.

Abdi O"zaslan et al [7] the study suggested that estimation of a living height can be made possible using various dimensions of the lower extremity. One must consider differences between populations in order to apply functions as such to others. Also any bony deformity acquired or congenital must be ruled out in order to formulate the statistical data for proper and firm interpretation so as to quote correctly the stature.

A study by Rastogi et al. [8] reveals that the Middle Finger Length can be used successfully to predict stature in the Indian population. The study shows that the middle finger length bears a significant relation to stature and can be an important tool for stature estimation. Significant differences in measurements and formulae for males and females were found. These differences were insignificant when values were 
compared between subjects of the same sex in north and south Indians and also between the dominant and non-dominant hand.

Lal CS et al. (1972) [9] worked on a population of 258 in north Bihar, whose ages ranged from 12 to 21 years, for the estimation of the height from the surface anatomy of the long bones e.g. the tibia and the ulna. The ulnar mean multiplication factor was comparable in all the series. They claimed that the ulnar multiplication factor was a better guide for the calculation of the height, when it was not definitely known as to which part of the country the individual belonged.

Akhlaghi et al. [10] also identified meaningful relation between the stature and upper limb dimensions $(p<0.05)$ in Iranian population. The correlation coefficients ranged from 0.310 to 0.696 in males and 0.299 to 0.735 in females which can be can be used for forensic pathologists and Anthropologists.

Devi S et al. (2006) [11] computed the correlation coefficient $(r=0.619$ for males and 0.584 for females) and the regression equation formula for the estimation of stature by using the upper arm length among the living population of the Maring tribes of the Pallel area in the Chandel district, Manipur.

Rajesh B et al (2013) [12] founded a significant correlation between finger length and stature. Pearson correlation between finger length and stature was higher among females than males. The findings of study indicate that index finger and ring finger lengths can be used successfully to predict living stature of an individual.

Meenakshi B [13]analyzed and attempted to derive a formula between length of humerus and total height of an individual and ended with the result showing definite correlation between the two.

Altayeb Abdalla Ahmeda,[14] studied the results indicating significant sexual dimorphism for all measurements. There was a positive correlation between upper limb measurements and stature $(p<0.01)$, which was highest for ulnar length. The accuracy of stature prediction ranged from \pm 3.54 to $5.85 \mathrm{~cm}$. The use of multiple regression equations gave better results than simple regression equations. This study provides new forensic standards for stature estimation from the upper limb measurements of Sudanese adults.

\section{CONCLUSION}

The study indicates that stature can be predicted accurately by linear/curvilinear and multiple regression analysis even when identity is unknown from RULL-a problem frequently encountered in medico legal investigations. Establishing identity of an individual when only some remains of the body arefound as in mass disaster, terror events, bomb explosions, accidents, wars etc. If either of the measurement is known the other can be calculated and this would be useful for forensic medicine experts and anthropologists. It will also help in establishing identity in certain civil cases. There are lot of variations in estimating stature from limb measurements among people of different region and race. Hence there is a need to conduct more studies among people of different regions and ethnicity, so that stature estimation becomes more reliable and identity of an individual is easily established. These regression equations can be routinely used for the estimation of stature from the fragmentary remains discovered.

\section{Conflicts of Interests: None}

\section{REFERENCES}

[1]. Mitra Akhlaghi, Marzieh Hajibeygi, Estimation of stature from upper limb anthropometry in Iranian population, J Forensic Leg Med. 2012 Jul;19(5):2804.

[2]. Malay Kumar Mondal, Tapan Kumar Jana, Susmita Giri (Jana), Hironmoy Roy. Height prediction from ulnar length in females: a study in Burdwan district of West Bengal (regression analysis).J Clin Diagn 2012 Oct;6(8):1401-4.

[3]. Jibonkumar, Lilinchandra. Estimation of stature using different facial measurements among the Kabui Naga of Imphal Valley, Manipur. Anthropologist 2006;8(1).

[4]. Pelin C, Zagyapan R, Yaz ýcý C, Kürkçüoglu A. Body height estimation from head and face dimensions: a different method. J Forensic Sci.2010.

[5]. Arun Kumar Agnihotri, Additional Professor, Smita Kachhwaha, Assistant Professor b , Krishna, Anishta Allock Estimation of stature from cephalo-facial dimensions by regression analysis in IndoMauritian population Journal of Forensic and Legal Medicine 2011;18:167-172. 
[6]. Ilayperuma, Nanayakkara, \& Palahepitiya. A model for the estimation of personal stature from the length of forearm. Int. J. Morphol., 2010;28(4):10811086.

[7]. Ozaslan, abdi, i.scan, m.yasar; özaslan, i.nci; tugcu, harun; koç, sermet. Estimation of stature from body parts. Forensic science international (online); Amsterdam 2003; 132(1):40-5.

[8]. Prateek Rastogi, Tanuj Kanchan, Ritesh G. Menezes, Medicine, Science and the Law, Midle finger length - a predictor of stature in the Indian population, J. Medicine, Science and the Law. 49(2).

[9]. Lal CS, Lala JK. Estimation of height from the tibial and the ulnar lengths in north Bihar. J Indian Med Association 1972 Feb 16;58(4):120-21.

[10]. Akhlaghi M1, Hajibeygi M, Zamani N, Moradi. Estimation of stature from upper limb anthropometry in Iranian population B J Forensic Leg Med. 2012 Jul;19(5):280-4.

[11]. Devi S, Das H, Purnabati BK, Singh SD, Devi J. Estimation of stature from the upper arm length among the Marings of Manipur. Ind Med J, Aug 2006; 100(8):271-73.
[12]. Rajesh Vaijnathrao Bardale, Taikhoom Mohammed Dahodwala, Vaibhav Digambar Sonar. Estimation of Stature from Index and Ring Finger Length J Indian Acad Forensic Med. October-December 2013;35(4). ISSN 0971-0973.

[13]. Meenakshi P. BorkarEstimation of height from the length of humerus in western region of Maharashtra.International Journal of Research in Medical Sciences Borkar MP. Int J Res Med Sci. 2014 May; 2(2):498-500.

[14]. Altayeb Abdalla Ahmeda, DataEstimation of stature from the upper limb measurements of Sudanese adults. Forensic Science International 2013;228(13):178.e1-178.e7

\author{
How to cite this article: \\ Sachin Tote, Sanjay Wanjari, Darshana Tote. ESTIMATION OF \\ STATURE FROM UPPER LIMB ANTHROPOMETRY IN \\ MAHARASHTRIANS POPULATION: A CADAVERIC STUDY. Int J Anat \\ Res 2017;5(4.3):4640-4644. DOI: 10.16965/ijar.2017.358
}

